\title{
Alessandro Valignano: educación, inculturación y adaptación en Japón
}

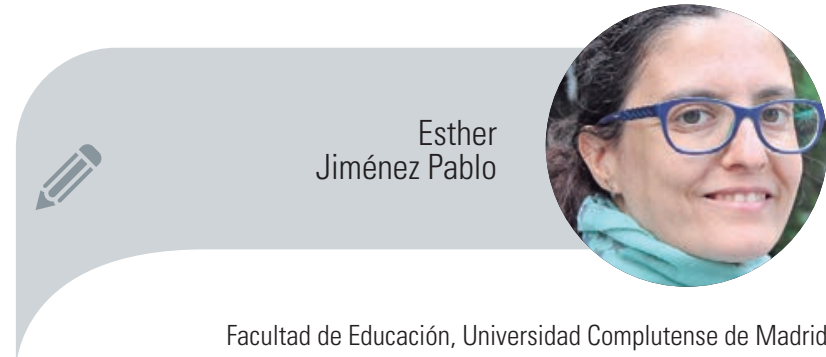

ejimenezpablo@ucm.es

En los años 90 se tomó conciencia de lo complejo que resultaba la llegada masiva de migrantes a nuestras costas. Sin duda, era muy difícil para la persona que debía abandonar su lugar de origen, pero también para el país de acogida, donde no existía un consenso ni político ni social en el modo de actuar. Esto enseguida tuvo su reflejo en las aulas, y los colegios comenzaron a recibir un alumnado diverso, hoy diríamos, multicultural, llegado de África, América y Asia. A partir de ahí, un esfuerzo colaborativo entre los centros educativos, privados o públicos, los docentes y la administración pública permitió dibujar las primeras líneas para la integración de los nuevos alumnos en el aula, y con ello, en nuestra sociedad. Todavía hoy dista mucho de ser una inclusión efectiva, a pesar de que el número de estudiantes foráneos sigue creciendo, y del entusiasmo que muchos docentes ponen de forma altruista. Quizá la clave sea más que el "respeto" en la cultura del compañero, que a veces es sinónimo de indiferencia, fomentar el interés en las culturas presentes en un aula, es decir, aspirar a una educación intercultural: generadora del intercambio de ideas y del diálogo entre culturas. Y de esto, mucho nos puede hacer reflexionar un maestro jesuita, el P. Alessandro Valignano, que viajó a Japón en el siglo XVI y cuyo método de inculturación -imbuyéndose en la cultura nipona - fue entonces muy criticado en Europa. Consiguió con ello cristianizar con éxito a una pequeña parte de la población, cosa que hasta entonces había sido muy difícil de conseguir por el hermetismo japonés. Hoy diríamos que este maestro reflejaba un gran interés por aprender de la cultura y costumbres del "otro".

\section{Valignano en Japón: camino a lo desconocido}

Un 25 de julio de 1579, llegaba al pequeño puerto de Kuchinotsu, en Nagasaki (Japón), un navío del que desembarcó un nutrido grupo de misioneros jesuitas con mucha ilusión y expectación, sin saber

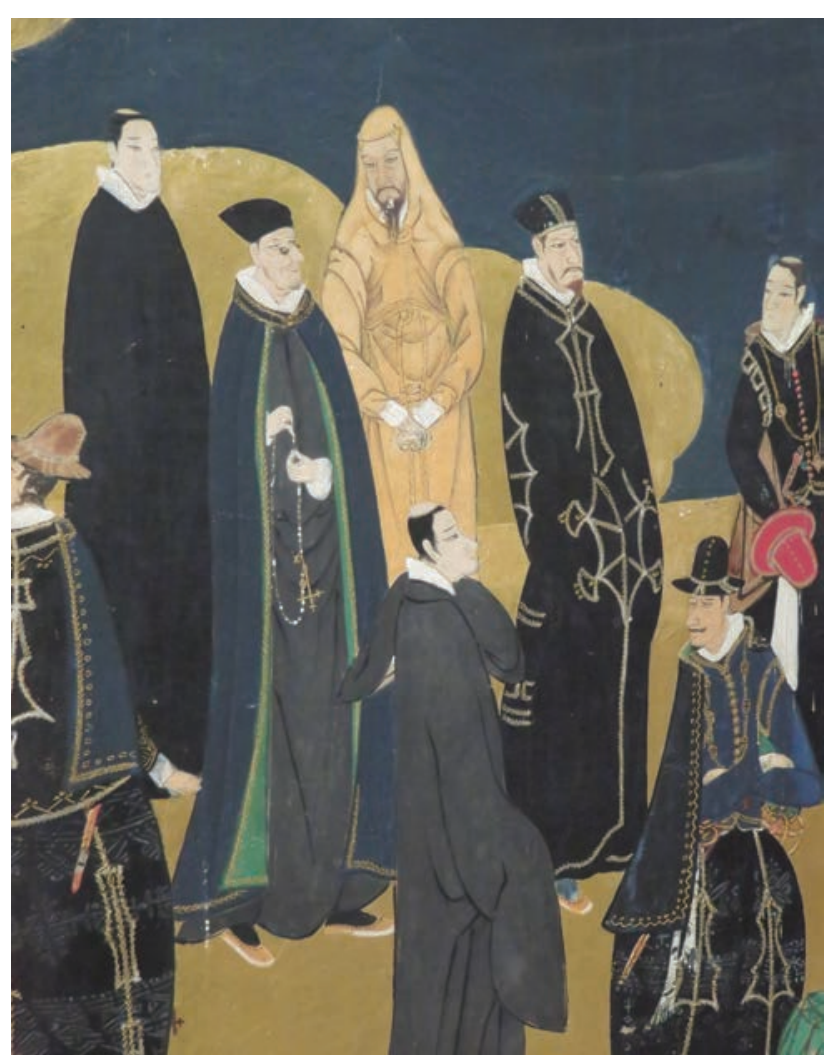

Jesuitas mimetizados con la cultura nipona en el puerto de Nagasaki. Biombo de arte Namban del Museo Nacional de Arte Antiguo de Lisboa. Foto de la autora

que estaban a punto de cambiar su mentalidad y su forma de enseñar y aprender. A la cabeza de la comitiva se encontraba el padre Alejandro Valignano, un napolitano (1539-1606) al que algunos historiadores han definido como un "intrépido maestro" y un "hábil estratega". Intrépido maestro porque sobrevivir a los largos viajes ultramarinos en la Edad Moderna era todo un logro, por no decir un milagro, y llegar a una tierra con una cultura totalmente distinta, de la que llegaban noticias de continuos martirios a religiosos occidentales, era toda una temeridad. Hábil estratega porque fue nombrado supervisor de las misiones en el Lejano Oriente y, como visitador de origen italiano, se ganó el respeto de los misioneros jesuitas, siendo todos portugueses o españoles, pues dependían de los barcos ibéricos que comerciaban con Japón para llegar a los puertos orientales y, por tanto, la nacionalidad de los misioneros en Asia quedaba restringida casi exclusivamente a 
religiosos hispano-portugueses. Fue, por tanto, de los pocos italianos a los que se les permitió llegar a Japón en el siglo XVI, acompañando de un total de 24 misioneros españoles y 18 portugueses.

\section{Descubriendo al maestro: una breve biografía}

Valignano nació en el seno de una familia noble de Chieti (Reino de Nápoles). Estudió derecho en la Universidad de Padua, entrando en la Compañía de Jesús en 1566. Como visitador en Oriente trabajó de manera incansable como atestiguan sus numerosas cartas y documentos, llenos de impresiones y fascinaciones ante las nuevas culturas, dejando pocas horas al día para el descanso y el sueño. Sus relatos y cartas son de gran valor etnográfico y antropológico, pues en ellos contrasta continuamente las costumbres orientales con las occidentales, sin encontrar apenas puntos de conexión. Visitó Japón un total de tres veces; la primera de 1579-1582, la segunda de 1590-1592 y la tercera de 1598-1603. A su muerte en Macao, en 1606, fue denominado de manera cariñosa "el apóstol de Japón".

\section{Su método de adaptación a una nueva cultura: jesuitas con kimono}

Su presencia en Japón significó un encuentro entre Oriente y Occidente, pero no en clave de imposición y choque cultural, sino desde la sintonía que provoca el diálogo y el sincretismo. No todo fue fácil, a su llegada tardó varios meses en comenzar a sociabilizar por la dificultad del idioma y de la cultura. Superado el primer año, como él mismo explica, se fue acostumbrando y las diferencias culturales fueron reduciéndose. Se habla así de un proceso de adaptación de la Compañía de Jesús a las costumbres orientales, definida como la accomodatio, de la que es artífice Valignano, entre otros, a la luz de su propia experiencia. Hasta entonces, los misioneros convertían al catolicismo a los nativos fomentando el aprendizaje del latín y de los ritos estrictamente cristianos, pues el camino emprendido por los conquistadores — pensemos en el caso de América - facilitaba la acción evangelizadora de los misioneros imponiendo su propia cultura. La sorpresa fue en Oriente, donde un proceso de conquista fue impensable, y mucho menos realizable, y la adaptación fue el único recurso que hizo posible la presencia de occidentales. Lo que propuso Valignano, no sin pocos obstáculos de algunos compañeros que no compartían este cambio de mentalidad, era adaptar la actividad de los misioneros de la Compañía de Jesús en el contexto de la Iglesia japonesa, mediante las costumbres de vida de la isla. Y para ello, Valignano tomó como re-

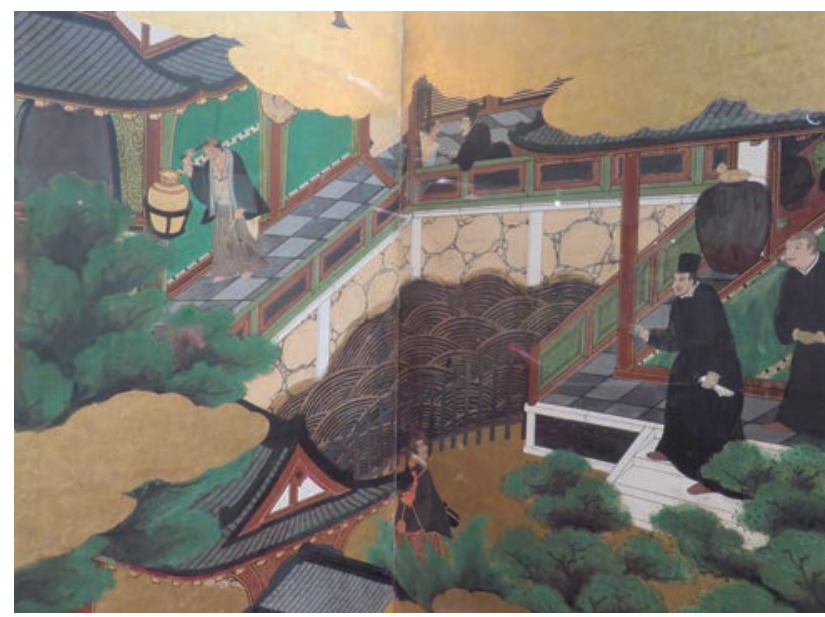

Seminario jesuita en lo que parece un templo budista, en sintonía con la naturaleza japonesa. Biombo de arte Namban del Museo Nacional de Arte Antiguo de Lisboa. Foto de la autora

ferencia las enseñanzas de "la prudencia" aristotélica unida a la "doctrina paulina" de un modelo de cristianización que se acomodaba a aquella sociedad en la que se intervenía. Valignano defendió que sus misioneros tendrían que aprender el idioma, la cultura, las costumbres y las formas de cortesía. Y aunque se pensaba ya entonces que Japón era un país avanzado, mantenía una férrea tradición difícil de comprender si no era viviendo igual que los japoneses el día a día. Un "parecer ser japonés" desde el respeto y el interés hacia su cultura para conseguir aprender de su forma de vida. Y con estas premisas, los jesuitas misioneros comenzaron a comer arroz en mesas bajas, a vestir Kimonos que utilizaban los bonzos - monjes budistas-, a sentarse en tatamis y a rehabilitar antiguos templos budistas o sintoístas como seminarios jesuitas.

De su método de adaptación destacan estas tres características:

$\boldsymbol{\lambda}$ La clave estaba en el idioma: en opinión de Valignano, lo primero y más importante era aprender a hablar, leer y escribir el japonés con soltura. Se planteó entonces crear cursos de dos años de duración con profesores nativos para aprender a fondo el japonés. Todos los misioneros recién llegados a Japón debían pasar por dichos cursos antes de enseñar el cristianismo a los nativos. Entiéndase mínimo dos años enteros por la dificultad de aprender los ideogramas japoneses. Algunos superiores jesuitas pensaban que era imposible aprender un lenguaje totalmente alejado de las lenguas latinas, pero en poco tiempo, Valignano mandó imprimir gramáticas, diccionarios bilingües y textos cristianos en japonés elaborados por los propios jesuitas.

入 La ayuda del clero nipón: como visitador buscó la manera de permitir que los nativos japoneses pudieran ser sacerdotes y misioneros. Era fundamental para el proceso evangelizador, no solo que los jesuitas se integraran en la sociedad japonesa sino 
"Y cuando nosotros decimos por qué gastan tanto dinero en estas cosas [Katanas, en occidente espadas] que de su naturaleza no tienen ningún precio ni valor, responden que lo hacen por la misma razón por que nosotros compramos un diamante o rubí por tan grande precio, de lo cual ellos no menos se espantan, diciendo que no es menor necedad ésta que la que nosotros les tachamos en comprar tales cosas por semejantes precios, antes dicen que las cosas que ellos compran y estiman tanto sirven para algún uso, y por eso es menos culpable su imaginación en dar por ellas tanto que la imaginación de los de Europa en comprar piedrecitas que no sirven para uso alguno.

También acostumbran todos los señores y caballeros, grandes y pequeños, luego que se casan sus hijos y llegan a diez y ocho o veinte años, entregarles el gobierno de sus casas y estados, recogiéndose ellos con alguna pequeña parte que reservan para sí, y ayudando a sus hijos con consejo. De lo cual, aunque por una parte se siguen grandes desórdenes gobernando comúnmente mancebos, los cuales, apartándose muchas veces del consejo de sus padres, hacen muchas imprudencias, todavía por otra parte se muestran en esto prudentes y de grande ánimo, renunciando tan fácilmente sus estados y mando y reduciéndose a vivir como particulares con descanso, cosa que pocas veces hacen en otras partes tan fácilmente.

Y finalmente tienen todos sus ritos y costumbres tan diferentes de las demás naciones que no se pueden fácilmente entender y aprender sino con mucho tiempo. Y cierto que es cosa maravillosa ver cómo pudieron inventar tal traje de vestir, tales comeres, tal manera de tañer y cantar y bailar, y otras mil ceremonias que ellos usan, que a toda suerte de gente son tan nuevas que por prudentes y sabios que sean los hombres se hallan en Japón niños e ignorantes, de manera que le es necesario aprender a hablar, a sentarse, a andar, a comer y hacer otras mil cosas nuevas, las cuales al principio parecen muy extrañas y fuera de razón, mas después que el hombre se acostumbra a ellas parécenle bien. Y están los japoneses tan casados con sus costumbres y ceremonias, que aunque se hunda el mundo no han de dejar ni un punto de su ordinario. Y a la verdad, proceder entre ellos de otra manera es descortesía y poca crianza, por lo cual los que no corren con sus costumbres son tenidos por hombres groseros, mal criados y de poca cuenta".

A. Valignano, Sumario de las cosas de Japón (1583) Capítulo I. De la descripción, costumbres y cualidades de Japón, en Monumenta Nipponica Monographs IX, Tokio 1954, pp. 49-52

que los japoneses pudieran ser religiosos cristianos. Esta fue una iniciativa muy criticada en Europa, incluso hizo dudar en distintos momentos al propio Valignano, pero allí tuvo éxito porque era un modelo de inclusión bidireccional, en el que el principal beneficio era que los japoneses convertidos al cristianismo agradecían confesarse con religiosos nipones. Se convirtió en una forma rápida y eficaz de aprender el cristianismo, pues ya estaban formados en la cultura y el idioma, además de conocer un espacio que dominaban a la perfección.

$\boldsymbol{\lambda}$ La creación de nuevos seminarios: el concepto de formar teológica y humanísticamente a futuros jesuitas se trasladó a Japón a través de los seminarios, que también se convirtieron en lugares donde

\section{(DA) DARB SABER MÂS}

Lisón Tolosana, C. (2005). La fascinación de la diferencia. La adaptación de los jesuitas al Japón de los samurái, 1549-1592. Madrid: Akal Ediciones.

Moran, J. F. (2012). The Japanese and the Jesuits: Alessandro Valignano in Sixteenth Century Japan. Londres: Routledge.

Tamburello, A., Üçerler, M. A., Dı Russo, M. (2008). Alessandro Valignano, uomo del Rinascimento: ponte tra Oriente e Occidente. Roma: Institutum Historicum Societatis lesu. aprender el estilo de vida y el idioma japonés. Independientemente de si eran nativos que querían ser jesuitas o estudiantes jesuitas de España o Portugal que habían viajado a Japón para seguir estudiando y comenzar a misionar allí, recibían sus clases en latín y japonés. Lo curioso era el escenario, es decir, aprender el cristianismo en un antiguo monasterio budista o sintoísta, rezando sobre un tatami, con objetos litúrgicos cristianos, pero de manufactura y decoración japonesa, como por ejemplo el uso del lacado. Así como rezar ante crucifijos en los que Cristo aparece con los ojos rasgados, para conseguir una mayor cercanía a la población.

Se podrá criticar o no este método, pero es el único que funcionó en Oriente, y con más razón en Japón, donde las persecuciones del Gobierno del shogunato Tokugawa, a partir de 1603, complicaron la presencia europea en sus tierras. Antes criticado, pero hoy, quizá, un modelo que nos hace reflexionar sobre el concepto de "interculturalidad" en nuestras aulas y sobre el interés por la cultura del compañero •

\section{HEMOS HABLADO DE}

\section{Educación; intercultural; intercambio; adaptación;} idiomas. 